\title{
Understanding emotionally relevant situations in primary dental practice.
}

\section{Emerging narratives}

Helen R Chapman ${ }^{\star 1,2}$ BDS, MSC

Susan Y. Chipchase ${ }^{3}$ BSc, MSc, PhD

Roger Bretherton ${ }^{4}$ BSc, DClinPsy

1. Paul Lowe Dentistry, 31 Farmhouse Way, Monkspath, Solihull B90 4EH

2. Visiting Fellow, School of Psychology, University of Lincoln, Brayford Pool, Lincoln LN6 7TS

3. Senior Lecturer, School of Psychology, University of Lincoln, Brayford Pool, Lincoln LN6 7TS

4. Senior Lecturer, School of Psychology, University of Lincoln, Brayford Pool, Lincoln LN6 7TS

*Correspondence to: Mrs Helen Chapman email: hchapman@lincoln.ac.uk 


\title{
Understanding emotionally relevant situations in primary dental practice.
}

\section{Emerging narratives}

\begin{abstract}
Background and Aims: Dentists experience considerable occupational stress. Stressful clinical situations can provoke high levels of negative emotions and situations which are associated with positive emotions tend to be overlooked by practitioners. Reflection regarding difficult situations is encouraged to facilitate learning. Cognitive behavioural therapy (CBT) formulations may be applied to situations appraised both positively and negatively. Analysis and interpretation of the dentist's coping behaviour and the consequent outcomes facilitate learning and reflection upon individual interactions with patients.

Method: Twenty primary care dental practitioners in the greater Lincoln area participated in a semi-structured interview which explored their stressful and positive clinical experiences. Some of the episodes were analysed to create CBT formulations.

Results and Discussion: CBT formulations are presented and the learning points highlighted by this structured presentation are discussed. In particular, it is suggested that this structured reconstruction of events, which highlights dentists' emotions, responses and the transactional effects of coping responses, might well facilitate objective reflective learning either individually or as part of peer to peer support. It should facilitate dentist's emotional processing of events and may thus contribute to stress reduction.

Conclusion: CBT formulations of positive and negative dental scenarios may be constructed. It is proposed that this is a useful technique to foster reflection and learning in clinical situations and should lead to improved communication skills and shared decision-making resulting in fewer complaints and thereby reduced stress. It should also improve dentists' emotional processing.
\end{abstract}




\section{INTRODUCTION}

This is the third in a series of papers exploring the nature of primary care dentists' emotions, coping and effects on their decision making in the clinical situation. The first two papers have discussed the stressors and accompanying emotions and the effects and coping strategies used. ${ }^{1 ; 2}$

Previous research with primary care dentists has considered the nature of stressful situations and the coping strategies used via questionnaires. ${ }^{3-5}$ This research is of limited usefulness as the responses are often generic, trait coping strategies.

Examples of the strategies included in these measures are 'interactions with people, sports and forgetting about work' ${ }^{3}$ or 'try to control the situation, pursue outside interests and re-interpret the situation positively'. ${ }^{5}$ However, these questionnaires fail to determine which coping strategy is used to cope with specific stressors. This is crucial as the coping strategies necessary to deal with different emotions may vary.

As previously described, ${ }^{1}$ many participating dentists referred to 'stress' as the major emotion they experienced at work. However, 'stress' is the perception of an overwhelming underlying emotion. ${ }^{6}$ Identification of this underlying emotion is essential in order to be able to address any differences in the way difficult situations are handled by dentists. The clinical situations previously described by dentists and reported in earlier papers ${ }^{1 ; 2}$ were initially interpreted within Lazarus and Folkman's model of stress, appraisal and coping. ${ }^{7}$ (Figure 1 )

Lazarus and Folkman ${ }^{7}$ define coping as "constantly changing cognitive and behavioural efforts to manage specific external and/or internal demands [stressors] that are appraised as taxing or exceeding the resources of the person." (p141) Coping includes all purposeful attempts to "manage" stress, "whatever their effectiveness." The resultant outcomes can include minimizing, avoiding, tolerating/ acceptance of a stressful situation as well as mastering it. These outcomes may be helpful or detrimental in the outcome they produce. In other words, outcomes may match the intended purpose, or not, and that may differ in the short and long terms. (Table 1)

As most commonly represented, Lazarus and Folkman's model ${ }^{7}$ is, essentially, linear. An event is subject to a primary appraisal or evaluation. Having established that a threat is present, the person then assesses whether s/he has the skills to deal with the situation; the process of secondary appraisal. If the person concludes that the situation will be difficult to cope with, a feeling of stress is generated.

\section{Situation $\rightarrow$ Primary Appraisal $\rightarrow$ Threat Present $\rightarrow$ Secondary Appraisal $\rightarrow$ Coping strategy}

However, Lazarus and Folkman ${ }^{8}$ acknowledge that the process can become circular, with the outcomes of one strategy, (for example the response of another person or the consequences of a behaviour) becoming the antecedent or stressor for the next attempt to manage the situation. The transactional nature of the coping process was further developed by Aldwin. ${ }^{9}$ These interactions can form a 'vicious circle. ${ }^{.10}$ The possibility of emotional vicious circles was previously reported by dentists. ${ }^{1}$ 
An alternative model of coping is given by Power ${ }^{11}$ who emphasises the importance of the functionality of coping strategies over an analysis of the behavioural or emotional focus. Strategies can be internal to the self, as in trying to slow one's breathing rate or external, such as ensuring one writes thorough, contemporaneous notes. (Table 2) This system is simple in comparison to Folkman and Lazarus' model and may facilitate reflection on coping effectiveness.

Cognitive behavioural models of the stress and coping process have been developed $^{6}$ and allow a dynamic conceptualisation of the interactional nature of the cognitive and behavioural strategies used and the transactional feedback effects (in/effectiveness) of these strategies (Figure 2), as implied by the Power and Lazarus and Folkman models. During the thematic analysis for this study it became apparent that, whilst this type of generic CBT model is helpful, some of the evolving situations could not be truly represented by them and that a full cognitive behavioural formulation would serve better, particularly when the situations described detailed ongoing interactions with patients. (A CBT formulation is a diagrammatic representation of events.) These idiosyncratic formulations can be cross-sectional or longitudinal. They serve to 'tease apart' the dynamics of a situation, allowing identification of moments in time and processes which have been less than helpful and might be amenable to change in the future. ${ }^{12} \mathrm{~A}$ basic, 5 areas, cross sectional formulation template is presented in Figure $3 .{ }^{13}$ This is commonly referred to as the 'hot cross bun' model which aims to convey the interactions between the string of unhelpful thoughts (negative automatic thoughts), behaviours, emotions and physiological changes which happen in response to a precipitating event. The situation is subject to the influence of environmental factors present. ${ }^{13}$

This cross-sectional model can then be expanded to reflect the evolving situation or 'story'. ${ }^{14}$

Reflection on case stories is encouraged in general medical practice ${ }^{15}$ as

'Clinical practice requires person management, system management and selfmanagement, as well as case management. Only stories can integrate and expand all these dimensions.' (p 863).

It is also held that,

'Examining one's responses, beliefs, and premises in the light of the situation at hand' ( $p$ 818)

forms an integral part of reflective practice. ${ }^{16}$ This is often via participation in a 'Balint Group' which enables them to

learn (1) to take responsibility for their own feelings and thoughts, (2) to realize how hard it is to observe their feelings and thoughts, and (3) to understand how easy it is to miss what other people say. ${ }^{17}(p 1)$

This process has recently been suggested as a basis for reflection amongst dentists. ${ }^{18}$ However, these groups 1 . are often based within psychoanalysis, ${ }^{19 ; 20}$ a concept outside most dentists' experience; 2 . require a group for participation; 3. 
require a a trained supervisor; and 4. members of the group usually receive training in how to effectively feedback within the group situation. Recently these supervised groups have lost the psychodynamic element and tend to focus on 'stories as case knowledge. ${ }^{15}$

CBT formulations are useful for dentists as they are based in an analysis of events, thereby structuring experiences as recommended for reflective practices. ${ }^{21}$ Recall of events is often haphazard and this technique allows an accurate sequence of events to be created. This can enhance the ability to identify problems such as communication failure with patients. The technique is easily learned by nonspecialists, as indicated by their wide use within the self-help literature. ${ }^{22 ; 23}$ It is therefore suggested that these formulations can be used by the individual dentist alone or with the help of trusted colleague/s to reflect upon and understand how difficult situations arose and might have been handled differently, thus learning from experience. ${ }^{15 ; 16}$ It has the additional advantage of being accessible within minutes or hours of the situation, without the delay of waiting for the next group session. This means that memories are fresher.

This study illustrates the application of CBT formulations to positively and negatively appraised dental scenarios in order to provide and analysis and interpretation of the events in terms of the dentist's coping behaviour and the consequences this produces. This process facilitates learning and reflection upon individual patient interactions. When an event is recounted, the retelling may not be completely logical and this is reflected in the quotations used and should help illustrate how the construction of a formulation reveals the decision points, chain of events, interactions and responses. It should also facilitate access to the technique by dentists.

\section{METHOD}

A detailed methodology is described in a previous paper. ${ }^{1 ; 2}$

\section{Participants}

Following ethical approval from the University of Lincoln, School of Psychology Ethics Committee, primary dental care practitioners within a 50 mile radius of the University of Lincoln were contacted via BDA Section Secretaries, editorial features in the dental press and 'snowballing'. ${ }^{24}$ Twenty dentists were contacted by telephone and interviews arranged at their practice.

\section{Procedure}

Semi-structured interviews covering positive and negative situations in the dental surgery, the emotions experienced, coping strategies used and their impact on decision making were conducted (SC), recorded and transcribed verbatim. They were then analysed and coded by $\mathrm{HC}$. The developed codes were organised into overarching themes. This was reviewed by SC and RB. Representative quotes were chosen by the 3 researchers.

One author $(\mathrm{HC})$ then constructed the formulation diagrams which were reviewed by RB. 


\section{RESULTS AND DISCUSSION Demographics}

Of the 20 dentists interviewed, 11 were female (55\%). Seventeen were general dental practitioners, of whom 6 were dental foundation (DF1) dentists and 3 worked for the Community Dental Services. The mean year of qualification was 1993 (range 1966-2011) with a mean number of years in primary dental care practice of 17.25 years (SD 13.23; range 1-46). Full details were given in a previous paper. ${ }^{1}$

\section{Thematic analysis}

Once dentists had described an emotionally relevant situation, a variety of probes were used to establish any responses used to manage the emotional situation and how the emotion affected the dentist.

The thematic analysis has been described in detail in 2 previous papers. ${ }^{1 ; 2}$ However, as the details of situations were elicited, "stories" emerged and it became apparent that some of these could best be summarised diagrammatically as cognitive behavioural (CBT) formulations. Representative formulations and the descriptions are presented here. The description of the situation will be presented in the dentists' own words. Some of the speech order has been edited for the sake of clarity. The dentists are identified as female to disguise identities.

\section{Case Formulations and Discussion of Coping}

\section{Positive emotions}

As described previously ${ }^{1}$, the experiences or challenges that were accompanied by these emotions were less well differentiated and were often reported as generic examples. The most common events which elicited positive emotions were successful skills transfer to patients and the success of technically difficult clinical work, especially if accompanied by a patient display of appreciation.

\section{Case 1: Happiness (Figure 4)}

Many dentists '... love doing the technical side, [getting] the technicals right.' [1:1] as illustrated below:

'The [new patient] ha[d] some absolutely [poor] fillings [in] her front teeth ... and we got rid of them. That's really exciting, 'cos ... she looked in the mirror and says "you've really made a difference." So ... where the patient's response is so positive ... that's the bit that gives you the buzz... [and] extreme excitement 'cos I love what I do .' [1:1]

A strong sense of pride in a job well done is implied.

As noted in an earlier paper, ${ }^{1}$ pride was often viewed as hubristic by dentists. Perhaps the apparently crucial appreciation by patients allows dentists to take delight, labelled as 'happiness' or 'excitement', in their work without feeling that they are 'blowing their own trumpets.' 1 The other function which explicit appreciation might address is to counteract the burden of the perceived negative image of the dentist. $^{25}$ 
The recognition and mental noting of this type of event is important as if fosters psychological resilience $e^{26 ; 27}$ and may well serve to reduce stress and improve health. ${ }^{28}$ A detailed analysis may help to elicit more details, thus fostering the development of an analysis which could be compared with a similar situation where the outcome was negative.

\section{Negative emotions}

As previously described ${ }^{1}$ a range of negative emotions are generally described as 'stress' by dentists. Identification of the underlying emotion is important as the coping strategies which are likely to be effective may differ between emotional experiences. $^{1 ; 7 ; 29}$

\section{Case 2: Anger (Figure 5)}

This lengthy description demonstrates just how destructive clinician anger can be in the dental surgery.

"[The patient] was having a lot of pain with her tooth, so we had a long chat about it and said, do we want to take the out tooth [or] ... start a root canal treatment. We got him out of pain by starting the root canal treatment. We're going to try and see him in a couple of weeks' time once it's settled down a bit and if the tooth is wobbly we were going to get rid of it, if it wasn't wobbly we were going to try and save it. He didn't book that next appointment, and he came a month later in pain and he confessed, I'm in loads and loads of pain, I want a prescription.

"Alarm bells were ringing in my head already because he's already said he wants a prescription, so anything else I knew he's not going to be happy with, he doesn't want me to touch him today. So I had a look at the tooth ... [and] there was no way I could save it. So I said, look you need this tooth out and ... he agreed. He said, 'I don't think you're going to be able to do it today', I don't think you'll be able to get me numb." I said, 'There's always a chance I won't be able to get it numb' and he kept saying this and I said it'd be wrong for me to give you a prescription and not try to take this tooth out and eventually he agreed, we'll try to take the tooth out."

The patient's request for a prescription and his insistence that the dentist would not be able to 'numb' him, threatened the dentist's professional self-esteem. Coupled with an entrenched and inflexible belief that a prescription was totally inappropriate in these circumstances, the dentist's only coping strategy was to 'stick to her guns' and doggedly pursue a path towards extraction, using explanations and clinical justifications (behavioural and problem-focused coping [and in this case] dysfunctional).

"Every time after I gave him an injection, he kept saying over and over again, 'that's not enough, you've not given me enough, I always have more than one injection' and l'd said, 'you're probably going to need more than one injection but I need to give it you one at a time' and I really tried with him. I tried to discuss the nerve distribution and everything, and so he just kept saying, 'I need more, I need more,' and so I tested that he was numb, and he wasn't, and at that point he said quite aggressively to me, 'I told you l'd need more anaesthetic'. And at that point I was really angry and I tried not to show it, and I said, 'Look I've explained to you what I'm trying to do', and at this point he was furious, I was obviously angry and I gave him a different injection. Whilst he was in the room I was trying to explain it to him, I mean it's not normal that I explain the anatomy of nerves to a patient, but after he'd said, I told you it wouldn't be enough and everything, and I gave him another injection ..." 
Once exhausted by the apparent battle of wills and the lack of success in achieving anaesthesia, the dentist turns to emotion-focused coping and sends the patient downstairs to wait for the anaesthesia to work, allowing her to distract herself (avoiding the emotion) by writing up the notes. One can only view this as dysfunctional, behavioural, emotion-focused coping as a patient who is this distressed is most likely to view this behaviour as rejection.

"I wanted to give it a good five or ten minutes to see if it was going to kick in a bit later on, so I did actually say, l'd be grateful if you could wait in the waiting room because this is going to take a bit longer and so I sent him downstairs. But I think our communication had broken down so much at that point that, he was only going to sit in the chair feeling a bit angry, I would rather write up the notes at that point."

And then the dentist finally capitulated.

"To cut a long story short, I couldn't numb the tooth and I had to give him a prescription."

The threat to this dentist's self-esteem (a common precipitator for anger-type emotions) $1 ; 30 ; 31$ and the consequent highly focused approach to get the tooth extracted meant that she didn't pause and consider, or ask, why the patient was so insistent that he would not go numb and needed a prescription. She failed to establish if this was based on previous experiences of difficult extractions and she failed to consider the possibility that this might be based in fear. This 'blinkered vision' that accompanies intense emotions, particularly negative ones, results in cognitive errors and poor decision making in clinicians. ${ }^{32 ; 33}$

To make matters worse, the dentist did not let matters rest; she had to have the final word.

"As he was walking away, I said to him, 'I know you're not happy with today because you wanted a prescription and you're walking away with one and you didn't want the bit in between but it would've been wrong for me to have given you a prescription without trying to take that tooth out, which it is going to come back you need to take it out' and he didn't look happy but he seemed to understand and he walked off and apparently I got told later that he was [complaining] to reception about it, saying that all he wanted was a prescription; I should've given it to him."

The parting shot of the dentist was based on the contemporaneous, widely held interpretation of clinical guidelines that one should not use antibiotics as a first choice of treatment in these circumstances. Whilst this is guideline was introduced to counteract the overuse of antibiotics in situations where other treatments were possible, the current GDC guidelines ${ }^{34}$ (which have been made more explicit since the interview) do allow for a certain amount of clinical discretion, as long as valid clinical reasons are recorded. Would it have been appropriate to prescribe antibiotics immediately at the second visit? It is not possible to make that judgement as the dentist failed to establish the reasons and beliefs underlying the patient's adamant request. If the patient were phobic with a previous history of failure to achieve adequate anaesthesia and/or difficult extractions, it possibly might have been.

And, of course, what many would view as the inevitable, occurred:

"Anyway because he was in a lot of pain with it, l'd booked him in up here, l'd gone to extra lengths so that I could see him within a week to take the tooth out after his prescription had started. ... On the day of the appointment he actually phoned my boss and made a complaint about me. The complaint being that he wanted a prescription and I didn't give it to 
him and he thought l'd belittled him because I kept saying, I knew what I was doing and I was trying to numb him up. So anyway it went back and forth, and I had to send letters and this, that and the other and it disappeared."

And despite all of this the dentist shows very little insight.

"I was angry at the time and I'm still quite angry about it. I'm glad he didn't come back because ... I would've had to pass my emotions ... I still felt like I gave him the best possible treatment, I felt like I tried to explain why I was doing what I was doing and he still didn't want to listen." [10:20-6]

The dentist obviously feels that she has communicated properly as she explained what she was doing. Unfortunately communication in dentistry is often viewed as the ability to convey information to the patient. ${ }^{35}$ However, an ability to listen is equally essential. ${ }^{36}$ Asking pertinent questions allows elicitation of the patient's knowledge (which may not be accurate), beliefs (which may be idiosyncratic and based on inappropriate information) and values (which may be surprising). Analysis of the situation via a CBT formulation allows a more objective reflection on events and allows identification of points in the time line where things might have been handled differently and the escalation of events curtailed.

Dentists often deal with the intense emotion of this type of event by 'venting' to colleagues. $^{2}$ Unfortunately, the research evidence ${ }^{37 ; 38}$ suggests that it is a counterproductive coping strategy which leads the person to subjectively feel better in that moment, but actually increases objective measures of anger in the longer term. Venting has been found to be associated with the 'overload' aspects of burnout. ${ }^{39}$ Structured reflection using a CBT formulation allows the processing of the emotion. ${ }^{40 ; 41}$

\section{Using CBT Formulations as a dentist}

The process of CBT formulation construction as part of therapy with a trained CBT therapist is a collaborative process; as part of self-help CBT, it is a personal process. The therapist can take another, less emotionally involved, perspective on the situation, reflect on what has happened and ask questions of the subject to encourage them to 'think around' what happened. In self-help CBT, the individual has to undertake this process on their own. This has the advantage of being entirely private and may save embarrassment and shame on the part of the individual which might act as a deterrent to sharing information. On the other hand a fresh pair of eyes, especially if far more experienced, can generate alternative interpretations of what happened and alternative examples of coping strategies which might have been used. This process might be of particular advantage to Foundation Dentists. Written, and ideally, face to face training should be received so that the process is understood before use in the clinical situation. Both methods of training have been piloted, as part of a selection of non-compulsory coping skills, with a mixed group of dentists (foundation and experienced primary dental care practitioners) as part of the evaluation of a coping skills package ${ }^{42}$ based on the needs identified in this study and a subsequent one. ${ }^{1 ; 2 ; 43}$ At six month follow-up 7\% of dentists who had written instructions only and $20 \%$ of those who attended additional face to face training were still using CBT formulations to reflect on, and understand, difficult scenarios as a 
coping skill of choice. This technique warrants further detailed evaluation, particularly with foundation dentists and their trainers.

\section{CONCLUSION}

As can be seen from these illustrated examples, situations as they arise in the dental surgery can be complex and on-going. The benefit of drawing out a CBT formulation of the situation over time allows events to be placed in sequence and accompanying emotions and thoughts to be sought and placed in context. A structured reflection regarding the events (self-directed or as part of a peer support process) can then occur, and can be used as a functional behavioural coping strategy in its own right. Such reflection should lead to improved reflection, learning, communication skills and shared decision-making within clinical practice, resulting in fewer complaints and thereby reduced stress.

\section{Acknowledgements}

The authors are indebted to the Shirley Glasstone Hughes Trust for funding this project and to the dentists who gave to generously of their precious time. They would also like to thank the anonymous peer reviewer for his/her helpful comments on an earlier draft of this paper.

Reference List

(1) Chapman HR, Chipchase SY, Bretherton R. Understanding emotionally relevant situations in primary care dental practice. 1. clinical situations and emotional responses. Br Dent J. In press 2015.

(2) Chapman HR, Chipchase SY, Bretherton R. Understanding emotionally relevant situations in primary dental care. 2. Reported reponses to emotional situations. Br Dent J. In press 2015.

(3) Ayers KM, Thomson WM, Newton JT, Rich AM. Job stressors of New Zealand dentists and their coping strategies. Occup Med (Lond) 2008 Jun;58(4):27581.

(4) O'Shea RM, Corah NL, Ayer WA. Sources of dentists' stress. J Am Dent Assoc 1984 Jul;109(1):48-51.

(5) Cooper CL, Watts J, Kelly M. Job satisfaction, mental health, and job stressors among general dental practitioners in the UK. Br Dent J 1987 Jan $24 ; 162(2): 77-81$.

(6) Brosan L, Todd G. Overcoming Stress - A self-help guide using Cognitive Behavioural Techniques. London: Robinson, 2009.

(7) Lazarus RS, Folkman S. Stress, Appraisal, and Coping. New York: Springer Publishing Company, 1984.

(8) Tetlock PE, Mitchell G, Murray TL. The challenge of debiasing personnel decisions: Avoiding both under- and overcorrection. Industrial and 
Organizational Psychology: Perspectives on Science and Practice 2008 Dec;1(4):439-43.

(9) Aldwin CM. Stress, coping, and development: An integrative perspective. New York, NY US: Guilford Press, 1994.

(10) Kappas A. Social Regulation of Emotion: Messy Layers. Frontiers in Psychology 2013;4.

(11) Power M. Emotion-Focused Cognitive Therapy. Chichester: Wiley-Blackwell, 2010.

(12) Grant A, Townend M, Mills J, Cockx A. Assessment and Case Formulation in Cognitive Behavioural Therapy. London: Sage Publications Ltd, 2008.

(13) Greenberger D, Padesky CA. Mind over mood: A cognitive therapy treatment manual for clients. New York, NY US: Guilford Press, 1995.

(14) Scott MJ, Stradling SG, Dryden W. Developing Cognitive-Behavioural Counselling. London: Sage Publications Ltd, 1995.

(15) Cox K. Stories as case knowledge: case knowledge as stories. Medical Education 2001 Sep;35(9):862-6.

(16) Poole G, Jones L, Whitfield M. Helping students reflect: Lessons from cognitive psychology. Advances in Health Sciences Education 2013 Oct;18(4):817-24.

(17) Balint E. The history of training and research in Balint groups. Psychoanalytic Psychotherapy 1985;1(2):1-9.

(18) Vergnes JN, Apelian N, Bedos C. What about narrative dentistry? Journal Of The American Dental Association (1939) 2015 Jun;146(6):398-401.

(19) Rabin S, Maoz B, Elata-Alster G. Doctor's narratives in Balint groups. British Journal of Medical Psychology 1999 Mar;72(1):121-5.

(20) Nielsen HG, Tulinius C. Preventing burnout among general practitioners: is there a possible route? Educ Prim Care 2009 Sep;20(5):353-9.

(21) Rogers RR. Reflection in Higher Education: A Concept Analysis. Innovative Higher Education 2001;26(1):37.

(22) Kennerley H. Overcoming Anxiety - A self-help guide using Cognitive Behavioural Techniques. Revised ed. London: Robinson, 2014.

(23) Williams C. Overcoming Anxiety, Stress and Panic - A Five Areas Approach. 2nd ed. London: Hodder Arnold, 2010.

(24) Goodman LA. Snowball Sampling. The Annals of Mathematical Statistics 1961;1:148-63. 
(25) Wilson RF, Coward PY, Capewell J, Laidler TL, Rigby AC, Shaw TJ. Perceived sources of occupational stress in general dental practitioners. $\mathrm{Br}$ Dent J 1998 May 23;184(10):499-502.

(26) Tugade MM, Fredrickson BL. Resilient individuals use positive emotions to bounce back from negative emotional experiences. J Pers Soc Psychol 2004 Feb;86(2):320-33.

(27) Tugade MM, Fredrickson BL, Barrett LF. Psychological resilience and positive emotional granularity: Examining the benefits of positive emotions on coping and health. J Pers 2004 Dec;72(6):1161-90.

(28) Bono JE, Glomb TM, Shen WINN, Kim EUGE, Koch AJ. Buiding positive resources: effects of positive events and positive reflection on work stress and health. Academy of Management Journal 2013 Dec;56(6):1601-27.

(29) Bamber MB. CBT for Occupational Stress in Health Professionals. Hove: Routledge, 2006.

(30) Chapman HR, Chipchase SY, Bretherton R. Understanding emotionally relevant situations in primary care dental practice. 1. clinical situations and emotional responses. Br Dent J 2014;submitted.

(31) Linehan MM. Skills Training Manual for Treaing Borderline Personality Disorder. New York: The Guilford Press, 1993.

(32) Croskerry $P$, Abbass A, Wu AW. Emotional influences in patient safety. J Patient Saf 2010 Dec;6(4):199-205.

(33) Janis IL, Mann L. Decision Making. New York: The Free Press, 1977.

(34) General Dental Council. Standards for the Dental Team. London: General Dental Council, 2013.

(35) Holden A. Lost in transition - changes in communication in the leap from dental student to foundation dentist. British Dental Journal 2011 Nov 25;211(10):459-61.

(36) Jackson C. Shut Up and Listen: A Brief Guide to Clinical Communication Skills. Dundee: Dundee Universtiy Press Ltd, 2006.

(37) Lohr JM, Olatunji BO, Baumeister RF, Bushman BJ. The psychology of anger venting and empirically supported alternatives that do no harm. The Scientific Review of Mental Health Practice: Objective Investigations of Controversial and Unorthodox Claims in Clinical Psychology, Psychiatry, and Social Work 2007;5(1):53-64.

(38) Stone AA, Kennedy-Moore E, Neale JM. Association between daily coping and end-of-day mood. Health Psychology 1995 Jul;14(4):341-9. 
(39) Montero-Marin J, Prado-Abril J, Piva Demarzo MM, Gascon S, GarciaCampayo J. Coping with stress and types of burnout: explanatory power of different coping strategies. PLoS ONE 2014;9(2):e89090.

(40) Wills F. Skills in Cognitive Behaviour Counselling \& Psychotherapy. London: Sage, 2008.

(41) Baker R, Owens M, Thomas S, Whittlesea A, Abbey G, Gower P, et al. Does CBT facilitate emotional processing? Behavioural and Cognitive Psychotherapy 2012 Jan;40(1):19-37.

(42) Chapman HR, Bretherton R, Chipchase SY. Too stressed to decide? The evaluation of a CBT self-help programme for dentists. The 42nd BABCP Annual Conference and Workshops . 2014. 7-23-0014.

Ref Type: Abstract

(43) Bretherton R, Chapman HR, Chipchase SY. Stress in primary dental care practice: Exploring specific stressors and the perceived requirements of a stress management training package. Br Dent J. In press 2015. 
Table 1 Examples of possible coping outcomes indicating whether a match or mismatch of intended purpose of coping occurs (Adapted from Chapman et a ${ }^{44}$ with permission)

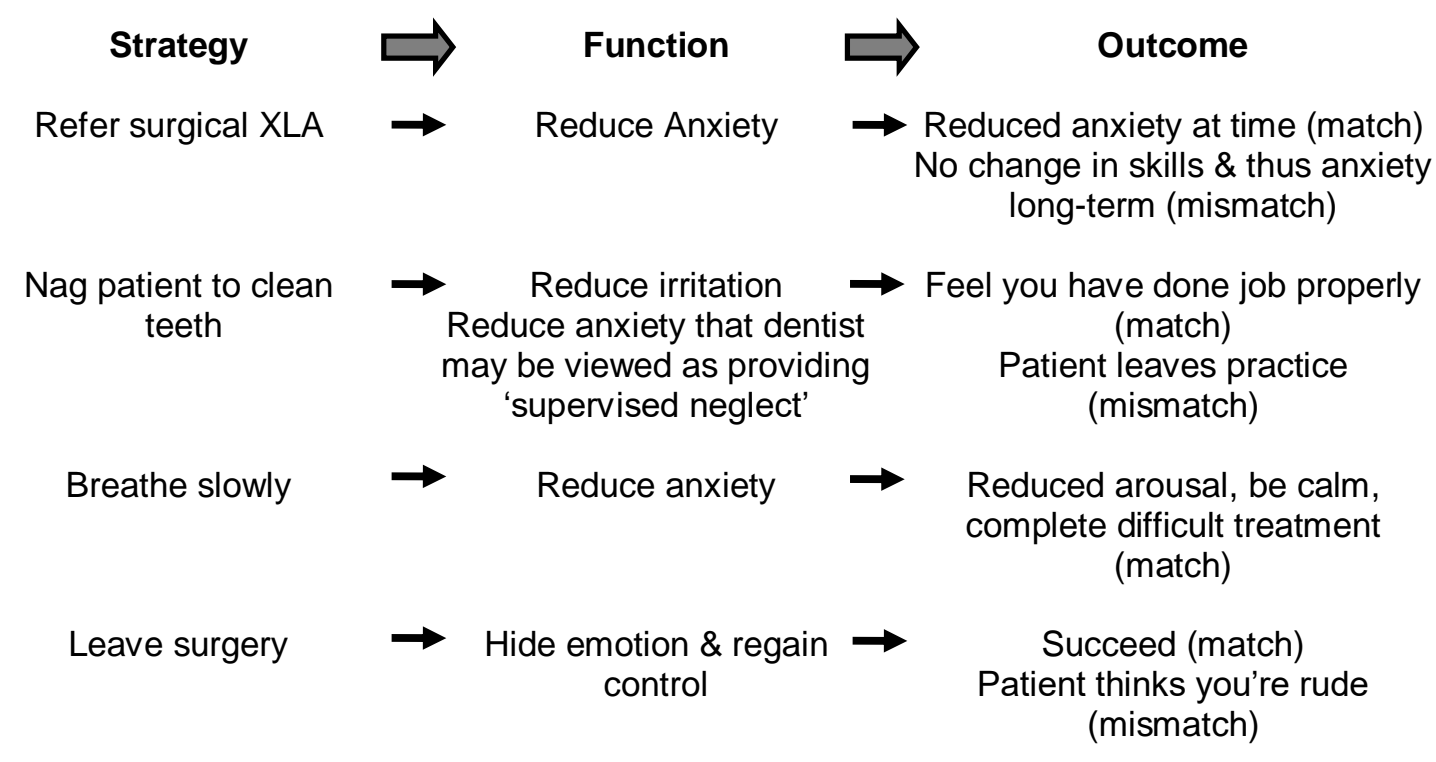

Table 2 Power's mode ${ }^{11}$ of emotional regulation strategies (Adapted from Chapman et al, ${ }^{44}$ with permission)

\begin{tabular}{|l|l|l|}
\hline & Internal & External \\
\hline Dysfunctional & Stop thinking. & Snap at nurse. \\
\hline Functional & $\begin{array}{l}\text { Pause before acting/saying. } \\
\text { Plan ahead. }\end{array}$ & $\begin{array}{l}\text { Listen to the patient. } \\
\text { Get advice from a colleague. }\end{array}$ \\
\hline
\end{tabular}


Figure 1 Lazarus and Folkman's model of coping ${ }^{7}$

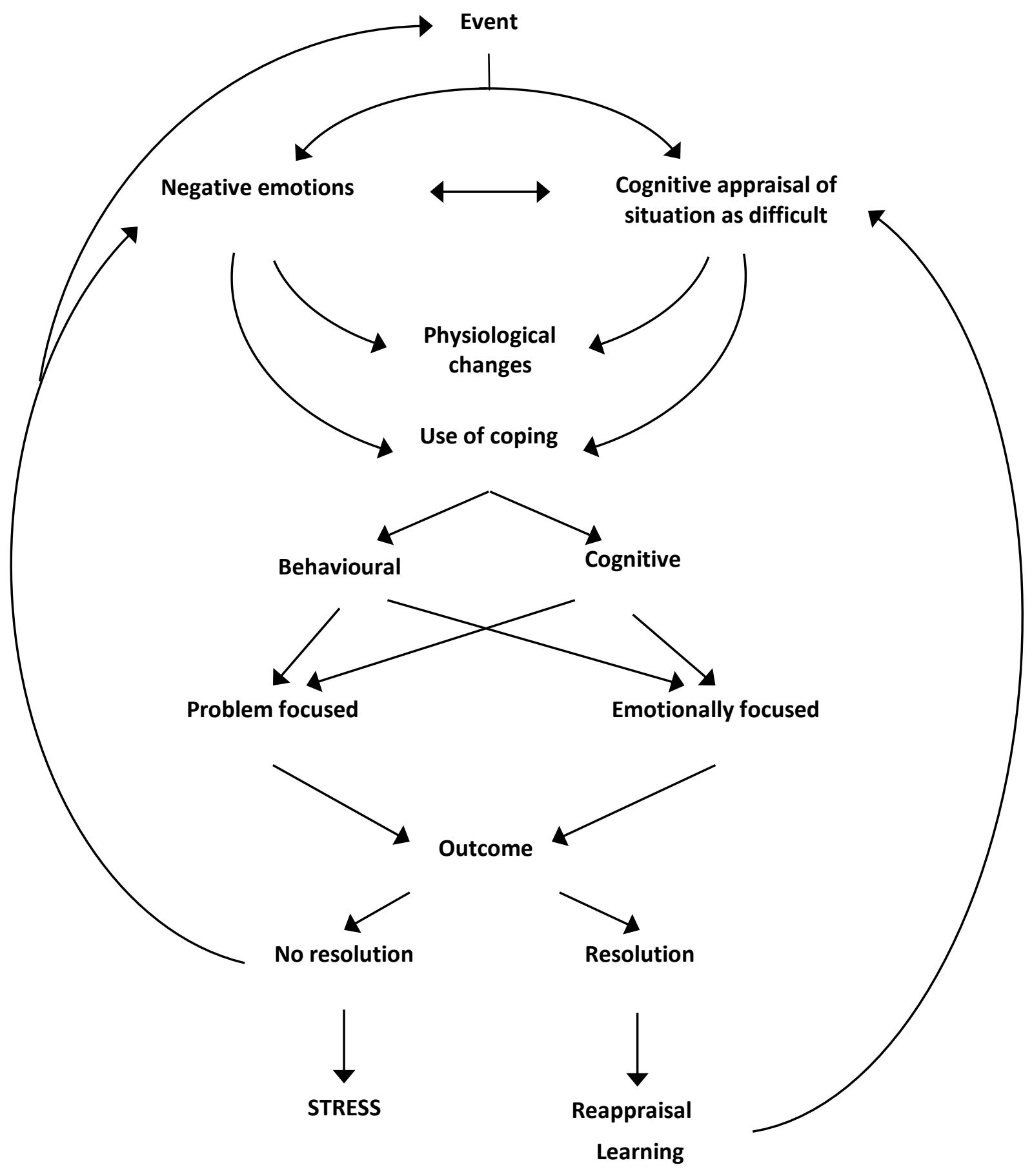


Figure 2 A cognitive behavioural model of a stressful situation (adapted from Brosan \& Todd $^{6}$ reproduced from Chapman et al $^{44}$ with permission)
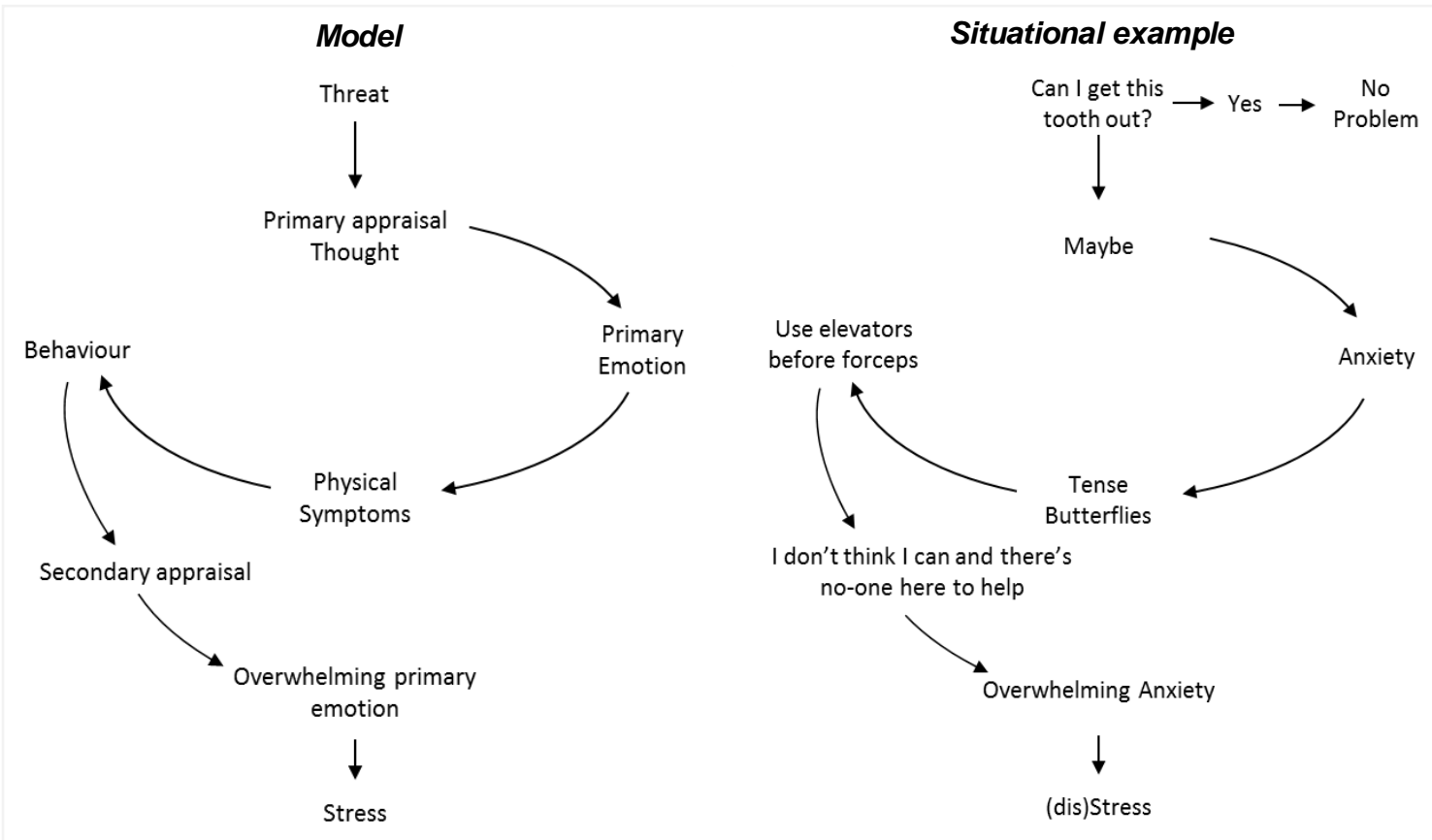

16 | P a g e 
Figure 3: A cross sectional cognitive behavioural formulation template based on Greenberger \& Padesky ${ }^{13}$

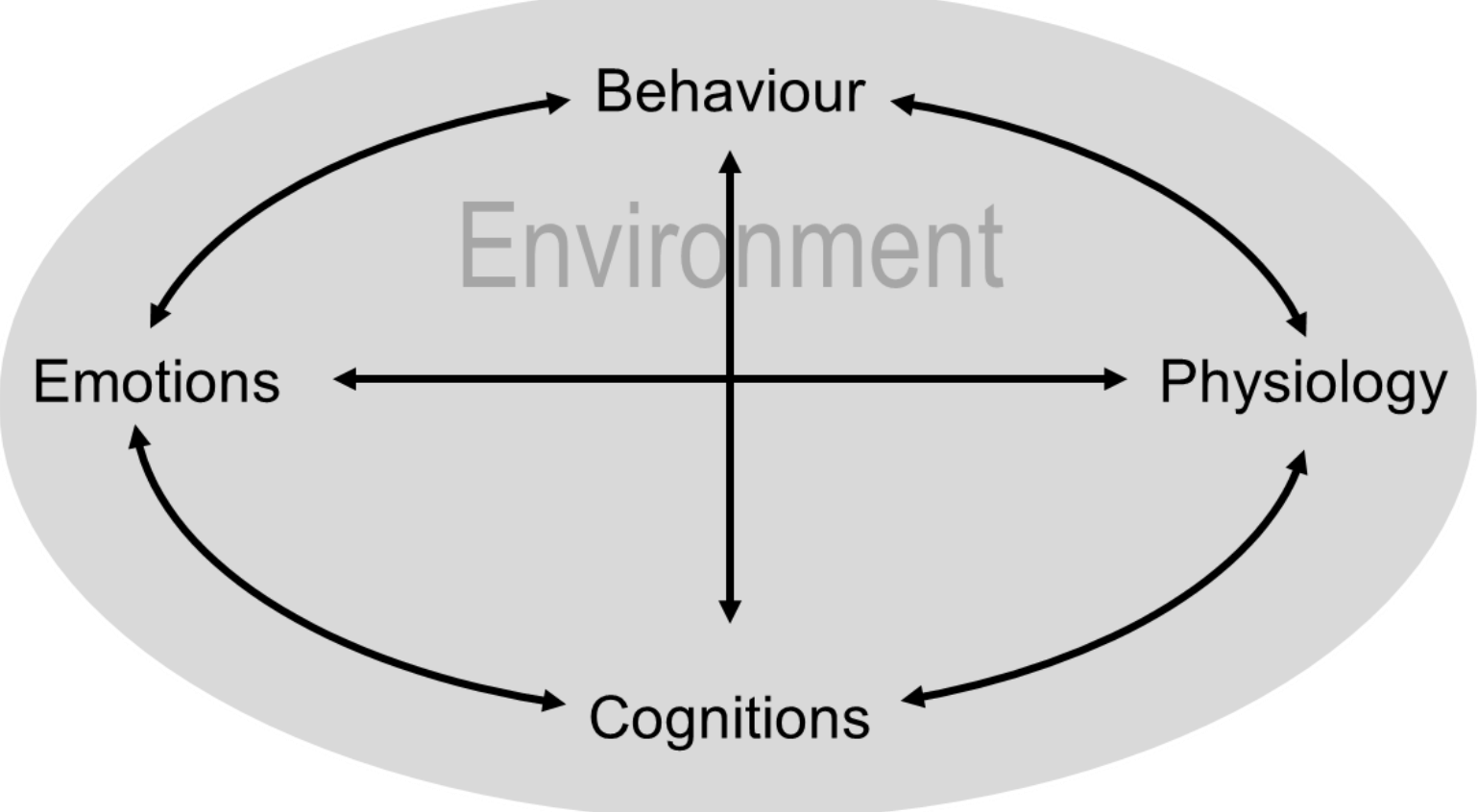


Figure 4 Case 2 - Happiness

Provide good quality restorations

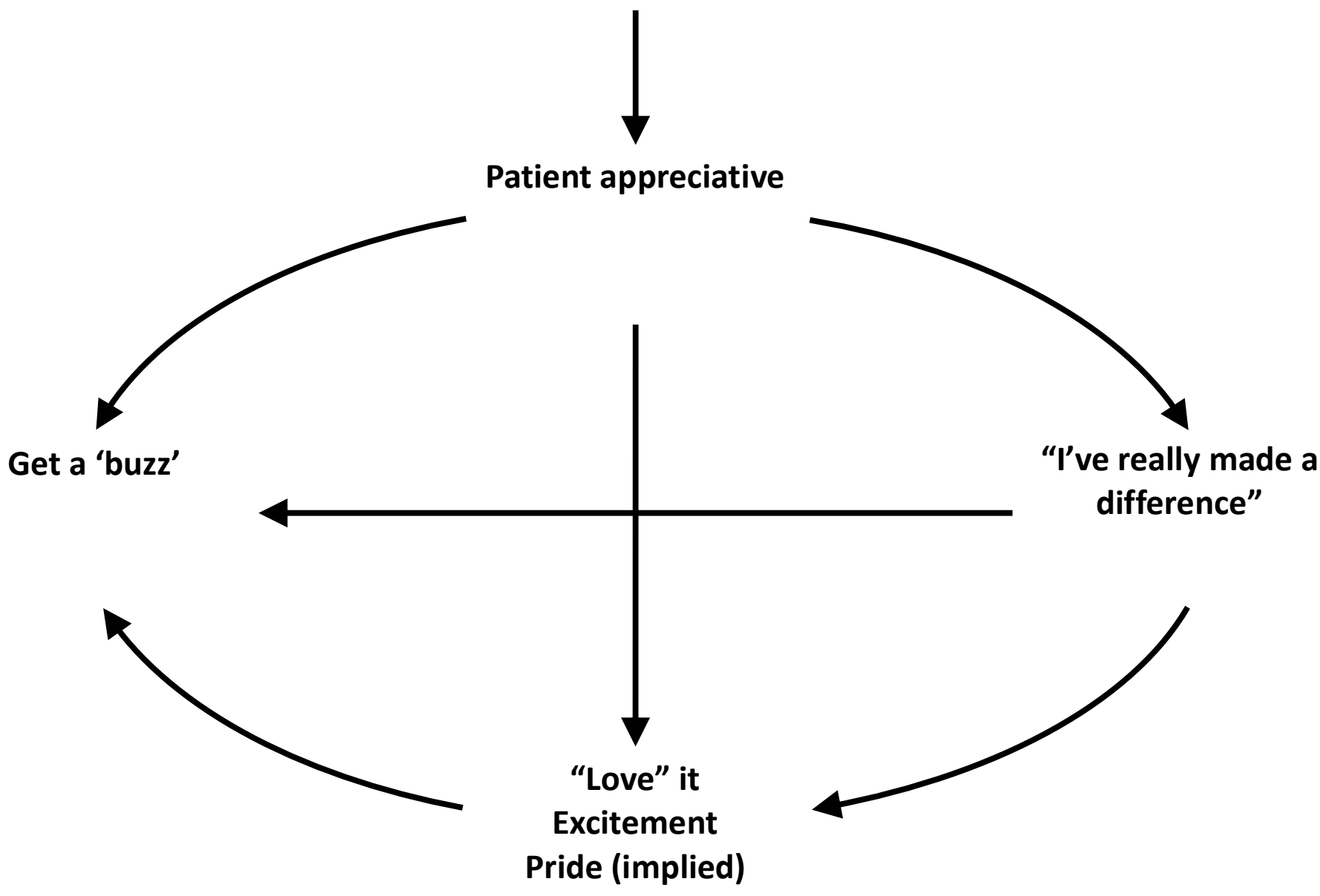


Figure 5 Case 2 - Anger

Patient in for review

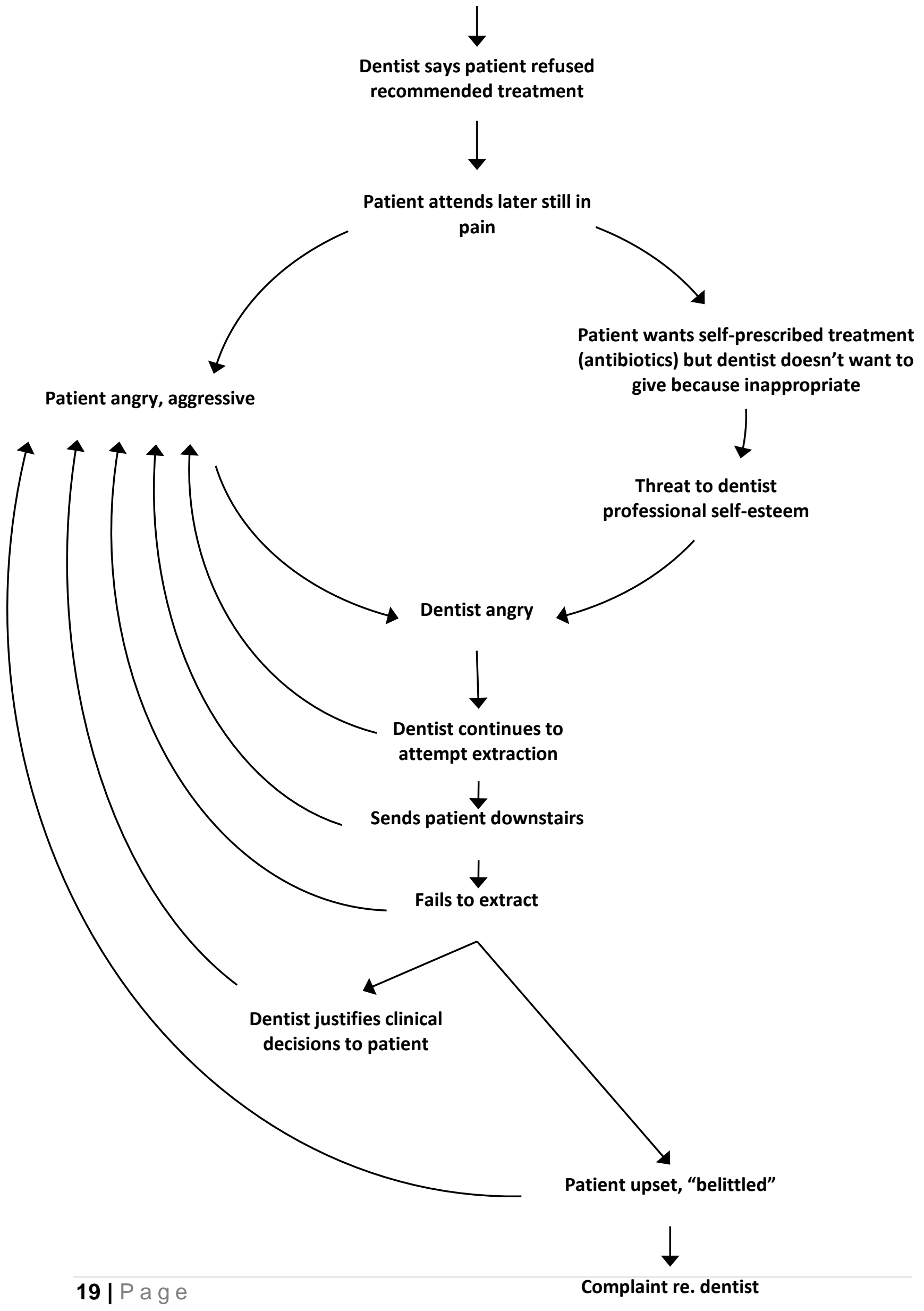

